\title{
Precipitation and air flow indices over the British Isles
}

\author{
D. Conway ${ }^{1, *}$, R. L. Wilby ${ }^{2}$, P. D. Jones ${ }^{1}$ \\ ${ }^{1}$ Climatic Research Unit, University of East Anglia, Norwich NR4 7TJ, United Kingdom \\ ${ }^{2}$ Department of Geography, University of Derby, Kedleston Road, Derby DE22 1GB, United Kingdom
}

\begin{abstract}
The relationships between regional daily precipitation time series in the British lsles and 3 indices of air flow are examined with a view to assessing their potential for use in GCM downscaling. These indices, calculated from daily grid-point sea-level pressure data, are as follows: total shear vorticity, a measure of the degree of cyclonicity; strength of the resultant flow; and angular direction of flow. The 3 indices, particularly vorticity, exert a strong control over daily precipitation characteristics such as the probability and amount of precipitation. There are significant regional differences in the relationships with precipitation, particularly between the England and Wales series and the Scotland and Northern Ireland series. Comparison of the relationships between air flow indices and regional and 2 single site precipitation series in England shows they are similar, although at the site-scale local factors may play an important role in affecting the relationships with the indices. Two models for generating daily precipitation series from vorticity are presented and evaluated by their ability to reproduce the following characteristics of precipitation over an independent validation period: annual totals and interannual variability, wel day probability and spell duration, and size of daily precipitation amounts. Model 1 is based on empirical relationships between vorticity and precipitation. Model 2 is based on user-defined categories of vorticity. The results for 2 sites (Durham and Kempsford) show that both models reproduce key characteristics of the observed daily precipitation series. Differences in model structure and number of parameters affect their accuracy in simulating the interannual variability and daily characteristics of precipitation. The air flow indices represent a significant advantage over tradjtional weather types because they are continuous variables. Previous downscaling techniques have relied upon classification techniques that impose artificial boundaries to define classes that may contain a wide range of conditions and no information about the intensity of development of the weather system concerned. As the 3 air flow indices are the basic determinants for describing the day's weather in many parts of the world, there is significant potential to apply this technique to other such regions. An example is shown of the relationships between daily precipitation in Switzerland and the air flow indices. The models may also be applied to the development of future daily precipitation scenarios using the coarse-scale output of GCM pressure fields.
\end{abstract}

KEY WORDS: Precipitation - Air flow indices - Vorticity - Downscaling Climate change

\section{INTRODUCTION}

The stimulus for this analysis stems from the need to develop methods for downscaling the output from Global Climate Models (GCMs) to the spatial and temporal resolution required for most climate impact studies. The general objectives and theory of downscaling are well described in the literature (see for instance Hulme et al. 1990, von Storch et al. 1993) Here we employ a new version of the circulation-type

•E-mail: d.conway@uea.ac.uk approach to downscaling that exploits the empirical relationships between circulation at the coarse GCM scale (typically of the order $500 \mathrm{~km}$ ) and weather at the regional and site scale. Our approach is developed from the work of Jones et al. (1993) on developing an objective version of Lamb's subjective classification of daily atmospheric circulation patterns over the British Isles [commonly referred to as Lamb Weather Types (LWTs); Lamb 1972]. LWTs have been related to spatial and temporal variations in precipitation (Wigley \& Jones 1987) and other environmental indicators such as acid rain (Davies et al. 1986) and surface ozone 
(O'Hare \& Wilby 1995). Wilby et al. (1994) and Wilby (1994) have specifically applied LWTs to the problem of downscaling and the synthesis of daily precipitation in the British Isles, whilst in other regions alternative classification schemes have been used (e.g. Bardossy \& Plate 1991, Hay et al. 1991).

These studies have highlighted a number of limitations to the approach, some inherent to the method in general and some inherent to the use of the LWTs scheme in particular. This paper deals with 2 of the key limitations

(1) The issue of temporal instability in the relationships between weather types and local weather. The relationship between a given weather type and the probability and magnitude of precipitation may vary over time. The periods used for model calibration and validation therefore need to be chosen with care. In order to develop future climate scenarios, it is necessary to assume that the observed relationships will hold in the future perturbed climate. Wilby (1994) and others have identified non-stationarities in the relationships between historic series of LWTs and local meteorological variables. Sweeney \& O'Hare (1992), however, found temporal variations in 20 yr mean precipitation yield for LWTs to be relatively minor. For cyclonic and westerly types, approximately $90 \%$ of 20 yr mean yields fell within $\pm 10 \%$ of the long-term mean. They suggested such changes could come about as a result of changes in mean trajectory or variations in sea surface temperatures. It is therefore foreseeable that the observed relationships will change in a future perturbed climate. This possibility is a serious limitation to any circulation-type method of downscaling. Indeed, this limitation will be inherent to any proposed downscaling method. Clearly, this is an important issue and there is much scope for further research into the causes of such non-stationary behaviour and for improving the estimates of the magnitude of such changes during the historic period.

(2) The difficulties of modelling the extreme characteristics of daily precipitation using classification schemes that do not incorporate a measure of the intensity of development of the weather system concerned. Previous methods of precipitation downscaling for the British Isles (e.g. Wilby 1995a) have favoured the use of discrete weather classification schemes such as that of Lamb (1972). Daily precipitation data have been categorised according to the prevailing circulation pattern or dominant precipitation mechanism (Wilby et al. 1995). The atmospheric circulation, however, is continuous and so the use of discrete categorisation within precipitation models has inherent limitations. In practice, there is often considerable overlap between the mean precipitation distributions of the most common circulation types such that they may be statistically indistinguishable. Neglecting the boundaries between such classes increases the size of calibration data sets at the expense of retaining the detail of rare precipitation events, in particular extreme precipitation amounts (Wilby in press). Conversely, a greater number of classes captures the uniqueness of less frequent circulation pattern-precipitation relationships but the statistical integrity is affected by small sample sizes. In addition, most weather-typing schemes do not provide any information about the intensity of the circulation system concerned or the precipitation amounts. This means that any given weather type will be associated with a considerable range of precipitation events. This in turn makes it difficult to simulate extreme events.

Recent work by Wilby et al. (1995) has attempted to improve the simulation of precipitation and account for some of the internal variations of precipitation yield with weather types by the incorporation of information on the passage of frontal systems along with the use of LWTs. Conway \& Jones (in press) and Wilby (in press) outline the potential for using the 3 air flow indices for the purpose of generating daily precipitation.

The 3 indices of air flow (vorticity, strength of flow and flow direction) provide an opportunity to model daily precipitation without the need for classification of circulation patterns into separate categories and the ability to take into account the intensity of development of the circulation system. This has the potential of enabling the method to be applied to other regions of the world subject to the availability of pressure data gridded at a resolution appropriate for the calculation of the air flow indices.

The objectives of this paper are two-fold. First, we present an analysis of the relationships between the characteristics of regional and single site daily precipitation and the 3 indices of air flow over the British Isles. Second, we assess the potential advantages of using these air flow indices, rather than traditional weather classification schemes such as the Lamb (1972) scheme, for the purpose of downscaling GCM output. These advantages are demonstrated by the application of 2 alternative daily precipitation models based on the air flow indices to the synthesis of daily precipitation at 2 sites in England (Durham and Kempsford). These methods are evaluated by their ability to reproduce the key characteristics of precipitation over an independent validation period.

\section{DATA}

The data-set used in this study comprises 9 regional area-average daily precipitation series, all spanning 


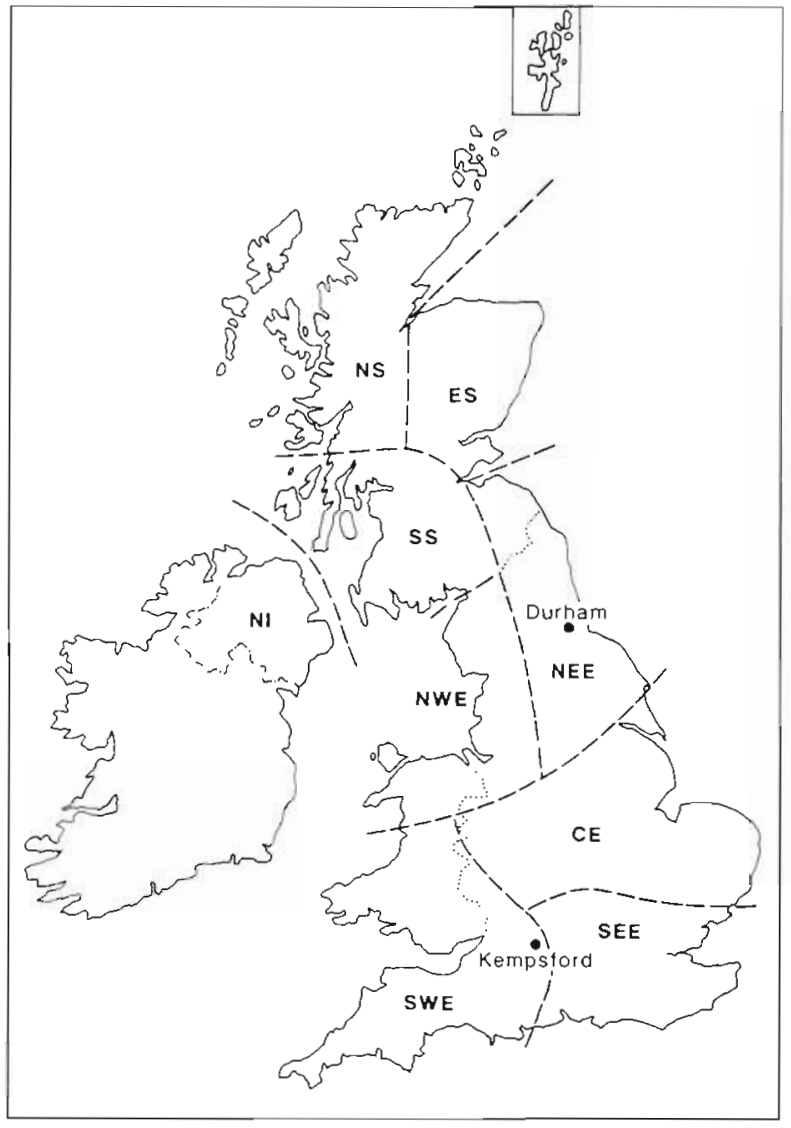

Fig. 1. Coherent precipitation regions in the British Isles and the locations of individual gauges used for the study

the common period 1931-1983, assembled by Wigley et al. (1984), Wigley \& Jones (1987) and Gregory et al. (1991). The regions possess spatially coherent precipitation as defined by principal components analysis. Each regional time series is based on a simple average of 7 sites. Fig. 1 shows the boundaries of the 9 regions and the locations of the 2 single sites (Durham and Kempsford) also used in the analysis, and Table 1 lists the abbreviations by which they are referred to in this study and their period of record.

The 3 air flow indices were used by Jones et al. (1993) to simulate objectively the subjective weather classification system developed by Lamb (1972) for use over the British Isles using daily grid-point sea-level pressure data obtained from a relatively coarse data-set $\left(5^{\circ}\right.$ latitude by $10^{\circ}$ longitude). In the objective 'Lamb' scheme the circulation is classified ac- cording to categories and thresholds of the 3 indices of air flow. These indices are as follows: total shear vorticity $(Z)$, a measure of the degree of cyclonicity (positive $Z=$ cyclonic conditions, negative $Z=$ anticyclonic conditions); strength of the resultant flow $(F)$; and angular direction of flow (D). The vorticity and flow units are geostrophic and expressed as hPa per $10^{\circ}$ latitude at $55^{\circ} \mathrm{N}$. Detailed explanation of the derivation of the air flow indices and their use is given in Jones et al. (1993).

\section{RELATIONSHIPS BETWEEN REGIONAL PRECIPITATION AND AIR FLOW INDICES}

Fig. 2 shows frequency distributions of the 3 air flow indices (divided into bins of various sizes) based on daily values (all days grouped regardless of season) calculated between 1881 and 1983 ( $\mathrm{n}=37620)$. There is a fairly even distribution of vorticity values, with a maximum frequency between about -5 and -15 (weakly anticyclonic). Strength and direction of flow possess more skewed distributions, with a maximum frequency of flow strength occurring between 10 and 12 units (roughly equal to between 6 and $7.5 \mathrm{~m} \mathrm{~s}^{-1}$ ) and a maximum frequency of flow direction between $255^{\circ}$ and $270^{\circ}$ from the north (i.e. preferentially westerly to southwesterly flow). Correlations between the air flow indices (not shown) indicate a weak positive relationship between vorticity and strength of flow but no relationships with flow direction.

Each of the 3 indices, particularly vorticity, exerts a strong influence on both the likelihood and the magnitude of precipitation events. The relationships with vorticity for the 9 regions are shown in Figs. $3 \& 4$. The regional plots all have the following characteristics: a marked increase in wet day probability (at 3 different thresholds: $>0,>1$ and $>10 \mathrm{~mm}$ ) with vorticity that is

Table 1 . The 9 regions and 2 sites with daily precipitation data used in the study

\begin{tabular}{|llc|}
\hline Abbreviation & \multicolumn{1}{c|}{ Region/site } & Period of record \\
\hline SEE & Southeast England & $1931-1983$ \\
SWE & Southwest England and South Wales & $1931-1983$ \\
CEE & Central and East England & $1931-1983$ \\
NEE & Northeast England & $1931-1983$ \\
NWE & Northwest England and North Wales & $1931-1983$ \\
SS & Southwest and South Scotland & $1931-1988$ \\
NS & Northwest and North Scotland & $1931-1988$ \\
ES & East Scotland & $1931-1988$ \\
NI & Northern Ireland & $1931-1988$ \\
- & Durham & $1881-1990$ \\
- & Kempsford & $1881-1990$ \\
\hline
\end{tabular}



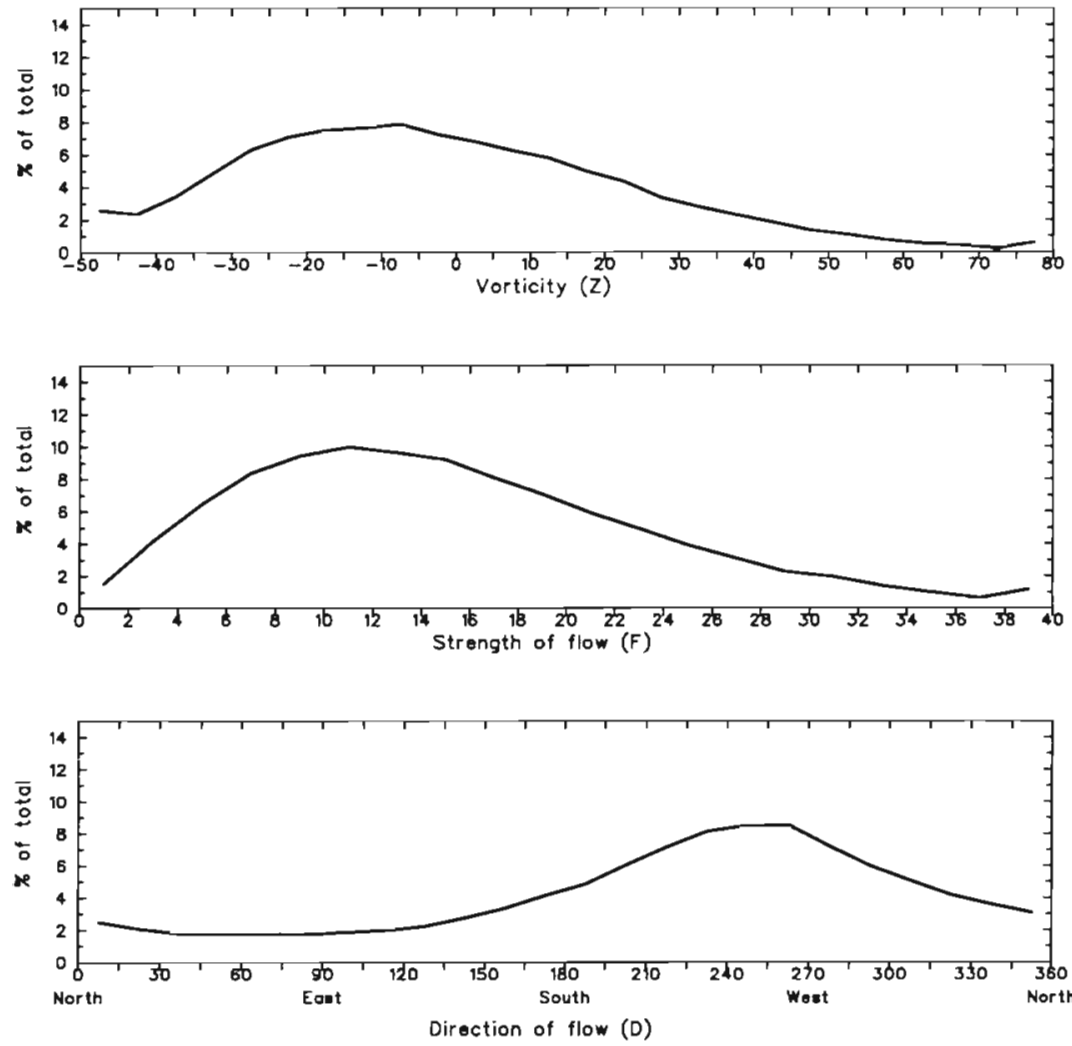

Fig. 2. Frequency distributions of air flow indices: vorticity (top); strength of flow (middle); direction of flow (bottom). Calculations based on the period $1881-1983$

greatest from about -25 to +15 units and levels out above roughly +30 ; and a more uniform increase in precipitation amount with increasing vorticity that is most pronounced with the $>0 \mathrm{~mm}$ wet day threshold. Above 60 and/or below -40 units there are less cases so it is difficult to generalise about precipitation characteristics associated with these events, although the trend towards fewer and smaller events and more and heavier events at the extreme values of vorticity is clear from Figs. 3 \& 4, respectively. Some regional differences exist in the relationships, particularly between the 5 England and Wales series and the 4 Scotland and Northern Ireland series. Wet day probabilities ( $>0$ and $>1 \mathrm{~mm}$ ) are generally higher in Scotland and Northern Ireland than in England and Wales for values of vorticity below -15 . Many of the differences in the absolute wet day probability and amount reflect the geographical variability of precipitation over the British Isles. These regional differences have also been noted with respect to the precipitation characteristics associated with LWTs (for instance, Sweeney \& O'Hare 1992).

All regions show an increase in the wet day probability with increasing strength of flow (Fig. 5). The rate of increase is greatest in the western regions and in most cases linear except for 3 of the Scottish regions. There is more regional variation in the relationships between strength of flow and the amount of precipitation (Fig. 6). For the England and Wales series, the 2 westerly regions (SWE and NWE) show an increase in precipitation catch, whereas the easterly series show no change with flow strength. Three out of the four Scotland and Northern Ireland series show marked increases (slight increase for NS) in precipitation catch, e.g. from roughly $2.6 \mathrm{~mm}$ with flow strength between 0 and 2 up to $9 \mathrm{~mm}$ with flow strengths greater than 38 . It is interesting to note the contrast between the easterly regions iñ England and Waies and the ES region where strong flows are associated with very high precipitation events.

Figs. $7 \& 8$ show, as we expected, the strong influence of flow direction on the probability and amount of precipitation. There are greater regional differences in these relationships than with vorticity and flow strength due in part to orography and rain shadow effects. The probability of precipitation in the 3 most southerly regions and NEE shows little dependence on flow direction although the frequency of heavy events $(>10 \mathrm{~mm})$ increases with southerly flow in SWE and easterly flow in NEE. The Scotland and Northern Ireland and NWE regions show a strong contrast between easterly (drier) and westerly (wetter) flows. There is even greater regional variation in the precipitation amount. The easterly regions in England and Wales record higher precipitation events with easterly and southerly flow. NWE, SS and ES record highest events with south westerly and westerly flow directions; SWE and NI are similar, but also record heavier events with south easterly flows

The relationships between 2 single site series (Durham and Kempsford) and air flow indices are generally consistent with their regional counterpart series. The relationships are shown for both sites between vorticity and mean wet day amount (Fig. 9) and vorticity and wet day probability (Durham. Fig. 10a, and Kempsford, Fig. 10b). Both the likelihood and amount of precipitation are clearly affected by the wet/dry state of the previous day. Relationships with flow strength and direction (not shown) indicate a greater influence from flow strength on precipitation at 

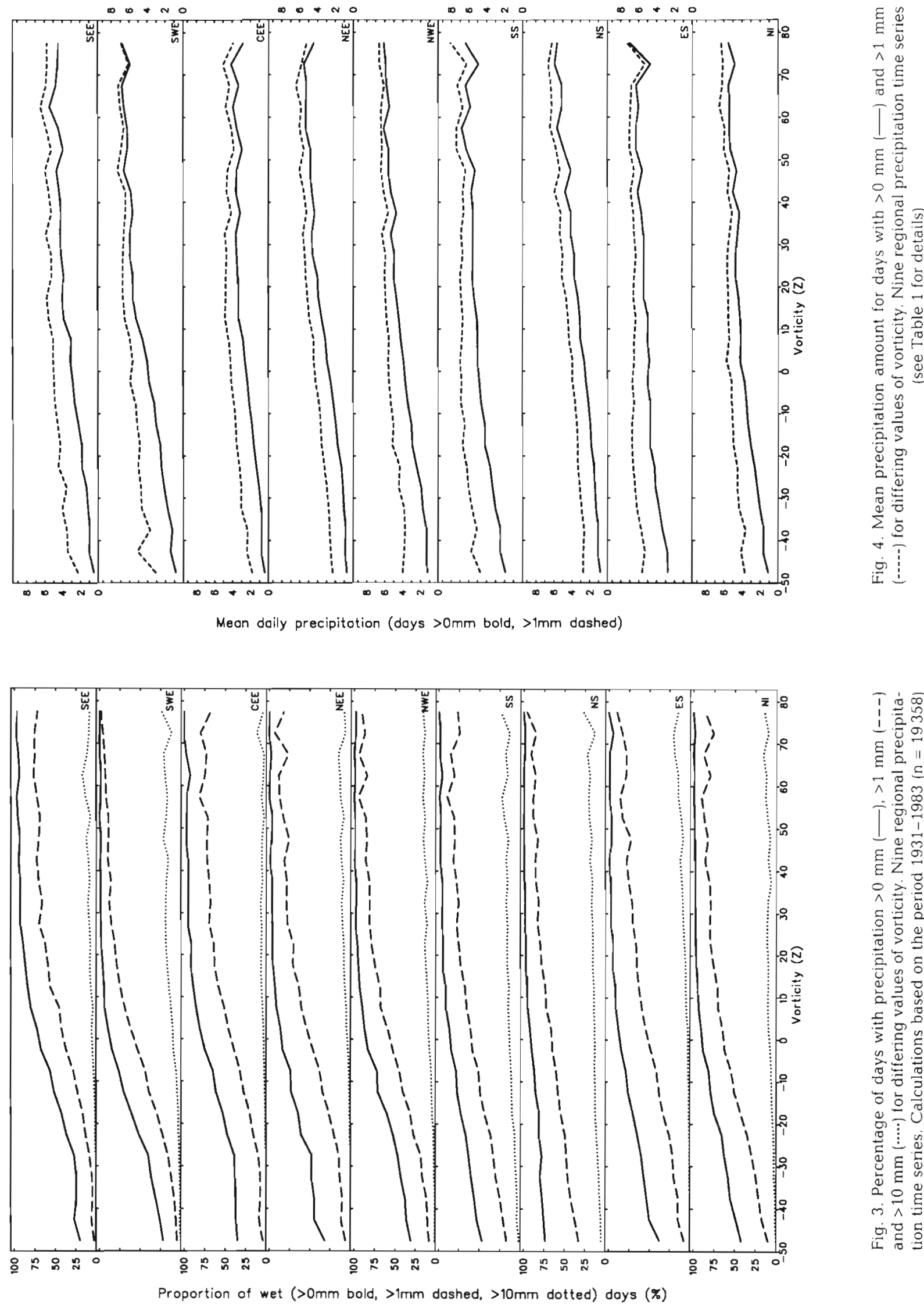





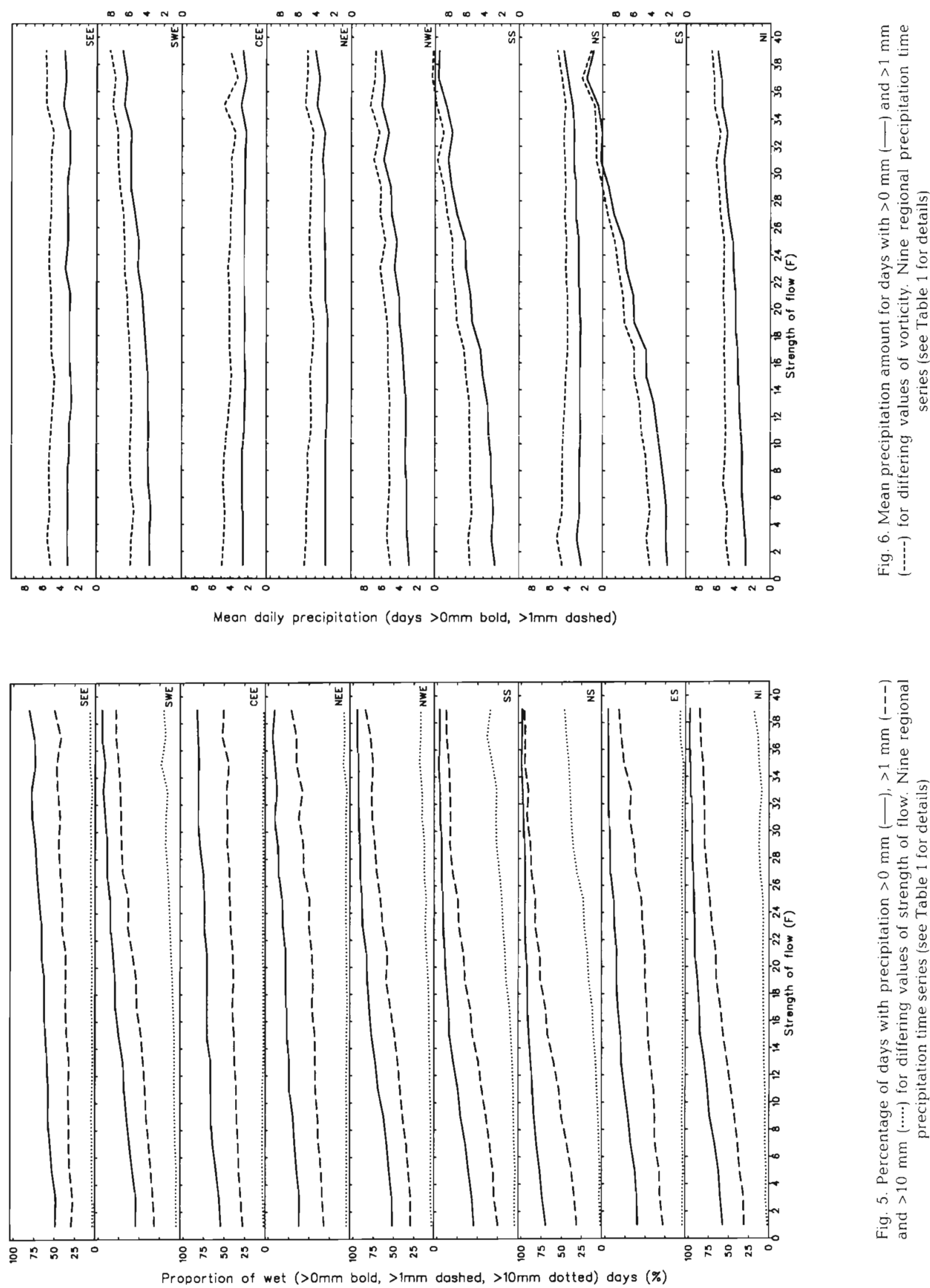

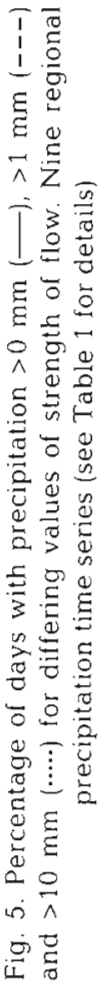



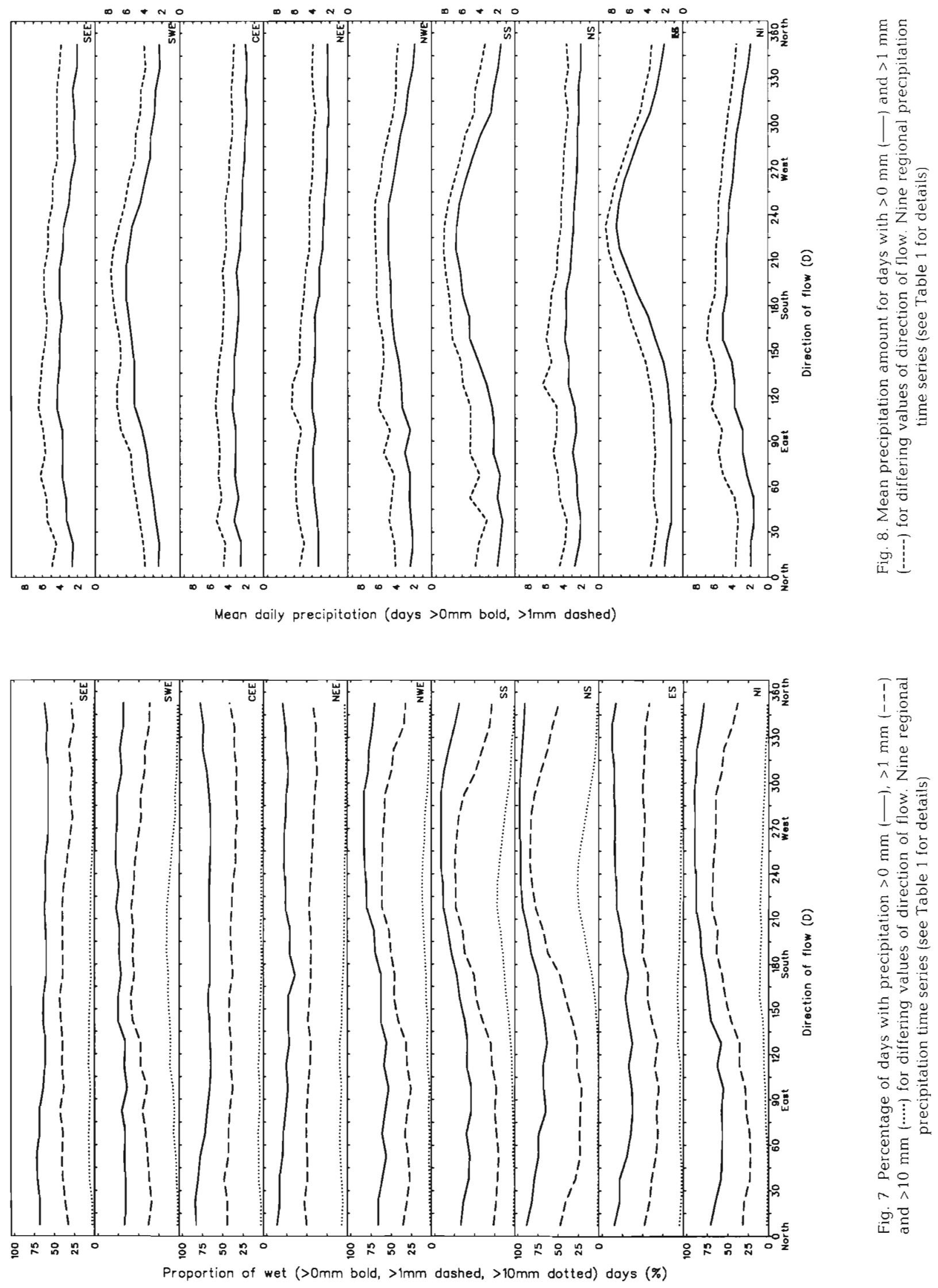
Kempsford, whereas precipitation at Durham is more affected by easterly flow.

\section{COMPARISON OF DAILY PRECIPITATION MODELS}

This section presents 2 alternative models for generating daily precipitation series from the air flow indices and a comparison of their performance based on the same calibration and validation periods for 2 single sites: Durham and Kempsford. The models are calibrated using the daily vorticity values and precipitation data at each site for the period 1881-1935 (55 vr). The models are then validated using only the daily vorticity values to simulate precipitation over the validation period (1936-1990). Wet days are defined as days with any measurable precipitation.

\subsection{Model 1}

Ideally, daily precipitation amounts should be related to a continuous atmospheric variable or variables, thereby avoiding the limitations of weather classification. Fig. 9 shows the relationship between the mean wet day amount and vorticity at Durham and Kempsford for the calibration period. This was modelled using a second-order polynomial regression. Similarly,
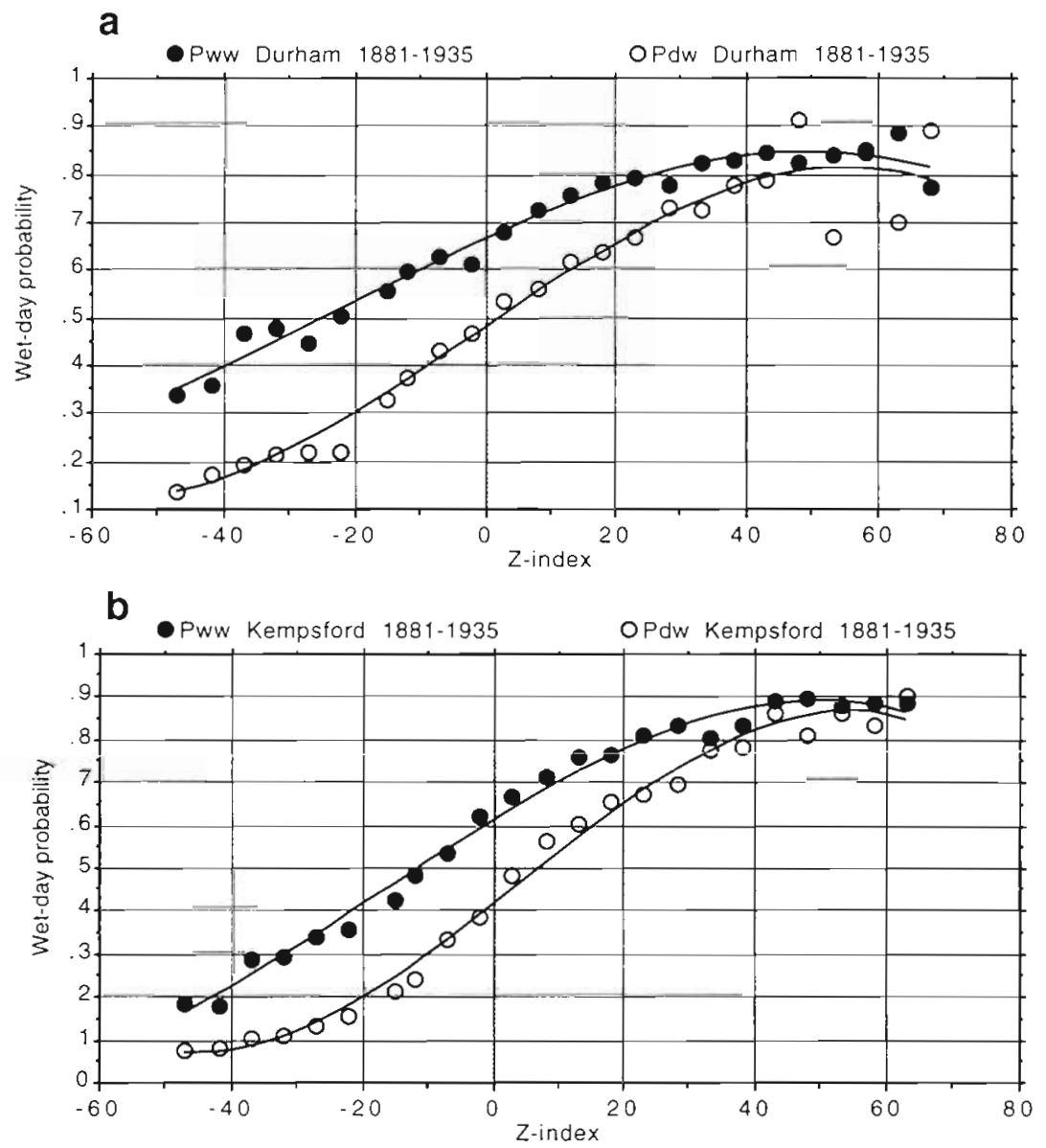

Fig. 10. Relationship between vorticity $(Z)$ and the probability of a wet day following a wet day (Pww) or a wet day following a dry day (Pdw) at (a) Durham and (b) Kempsford (1881-1935)

Fig. 10 shows the dependence of the probability of a wet day following a wet day (Pww) at both sites, which is represented by a third-order polynomial regression equation. The probability of a wet day following a dry day (Pdw) is, on average, lower at both sites for negative vorticity values but converges on a stable value for both Pww and Pdw when vorticity $>50$ units. The apparent instability in the relationships for very high vorticity values was attributed to the relatively few calibration events (Fig. 2). By using the polynomial equations derived from Figs. 9 $\& 10$, as well as a series of daily vorticity values, it is possible to determine daily precipitation amounts at the calibration sites using the following procedure:

(1) Input daily vorticity values (whether observed or GCM output).
Fig. 9. Relationship between the mean wet day amounts at Durham and Kempsford (1881-1935) and differing values of vorticity $(Z)$ 
(2) Determine the probability of precipitation (Pwet) using the vorticity value of the current day and polynomial equations for either Pdw or Pww (Fig. 10), depending on whether or not the previous day was wet or dry respectively. If vorticity $>50$ then Pwet equals a constant that is site specific.

(3) Precipitation occurs if $r_{1} \leq$ Pwet where $r_{1}$ is a uniformly distributed random number $(0 \leq r \leq 1)$.

(4) If precipitation occurs, the mean $24 \mathrm{~h}$ amount $(R)$ is determined using vorticity and the polynomial equation for $R$ (Fig. 9).

(5) The daily precipitation amount (ppt) is then modelled using $p p t=-R \cdot \ln \left(r_{2}\right) \cdot 2 r_{3}$ where $r_{2}$ and $r_{3}$ are linear random numbers as above. The term $\left(2 r_{3}\right)$ is used to increase the variance of the simulated precipitation amounts as in Hay et al. (1991).
Thus Model 1 stochastically generates site-specific, daily precipitation data from an input vorticity series. The model was used to synthesise daily precipitation probabilities and size distributions at Durham and Kempsford. No direct attempt was made to reproduce seasonality in the observed precipitation time-series; this was inherently represented by temporal variations in vorticity.

\subsection{Model 2}

The method consists of generating distributions of precipitation (or absence of precipitation) events for categories of air flow indices from the historical record (Conway \& Jones in press). Distributions are gener-

Table 2. Model 2 distribution (bin) sample size by season (DJF: Dec, Jan, Feb; MAM: Mar, Apr, May; etc.) for 10 classes of vorticity and with dry days following wet days (Pdw) and wet days following wet days (Pww) at Kempsford, from 1881 to 1935

\begin{tabular}{|c|c|c|c|c|c|c|c|c|c|c|}
\hline \multirow[t]{2}{*}{ Season } & \multicolumn{10}{|c|}{ Vorticity } \\
\hline & $<-40$ & $\begin{array}{c}\geq-40 \text { to } \\
<-30\end{array}$ & $\begin{aligned} \geq & -30 \text { to } \\
& <-20\end{aligned}$ & $\begin{array}{l}\geq-20 \text { to } \\
<-10\end{array}$ & $\begin{array}{c}\geq-10 \text { to } \\
<0\end{array}$ & $\begin{array}{l}\geq 0 \text { to } \\
<10\end{array}$ & $\begin{array}{l}\geq 10 \text { to } \\
<20\end{array}$ & $\begin{array}{c}\geq 20 \text { to } \\
<30\end{array}$ & $\begin{array}{c}\geq 30 \text { to } \\
<40\end{array}$ & $\geq 40$ \\
\hline \multicolumn{11}{|l|}{ DJF } \\
\hline Pdw & 392 & 404 & 436 & 404 & 281 & 219 & 132 & 89 & 42 & 45 \\
\hline Pww & 100 & 133 & 213 & 267 & 317 & 325 & 319 & 258 & 209 & 377 \\
\hline \multicolumn{11}{|l|}{ MAM } \\
\hline Pdw & 162 & 317 & 545 & 512 & 474 & 315 & 206 & 116 & 51 & 36 \\
\hline Pww & 33 & 80 & 138 & 245 & 340 & 360 & 355 & 276 & 205 & 294 \\
\hline \multicolumn{11}{|l|}{ JJA } \\
\hline Pdw & 22 & 200 & 547 & 665 & 586 & 387 & 247 & 131 & 60 & 22 \\
\hline PwW & 1 & 19 & 99 & 243 & 383 & 401 & 391 & 296 & 197 & 163 \\
\hline \multicolumn{11}{|l|}{ SON } \\
\hline$P d w$ & 191 & 360 & 516 & 465 & 369 & 262 & 177 & 95 & 61 & 41 \\
\hline PwW & 60 & 106 & 196 & 276 & 353 & 359 & 326 & 269 & 199 & 324 \\
\hline
\end{tabular}

Table 3. Model 2 distribution (bin) sample size by season for 10 classes of vorticity and with dry days following wet days (Pdw) and wet days following wet days (Pww) at Durham, from 1881 to 1935

\begin{tabular}{|c|c|c|c|c|c|c|c|c|c|c|}
\hline \multirow[t]{2}{*}{ Season } & \multicolumn{10}{|c|}{ Vorticity } \\
\hline & $<-40$ & $\begin{array}{c}\geq-40 \text { to } \\
<-30\end{array}$ & $\begin{array}{c}\geq-30 \text { to } \\
<-20\end{array}$ & $\begin{aligned} \geq & -20 \text { to } \\
& <-10\end{aligned}$ & $\begin{array}{c}\geq-10 \text { to } \\
<0\end{array}$ & $\begin{array}{l}\geq 0 \text { to } \\
<10\end{array}$ & $\begin{array}{l}\geq 10 \text { to } \\
<20\end{array}$ & $\begin{array}{c}\geq 20 \text { to } \\
<30\end{array}$ & $\begin{array}{c}\geq 30 \text { to } \\
<40\end{array}$ & $\geq 40$ \\
\hline \multicolumn{11}{|l|}{ DJF } \\
\hline$P d w$ & 318 & 348 & 363 & 335 & 263 & 228 & 148 & 95 & 49 & 51 \\
\hline Pww & 174 & 189 & 286 & 336 & 335 & 316 & 303 & 252 & 202 & 371 \\
\hline \multicolumn{11}{|l|}{ MAM } \\
\hline$P d w$ & 135 & 262 & 432 & 451 & 406 & 271 & 198 & 105 & 55 & 32 \\
\hline Pww & 60 & 135 & 251 & 306 & 408 & 404 & 363 & 287 & 201 & 298 \\
\hline \multicolumn{11}{|l|}{ JJA } \\
\hline$P d w$ & 21 & 177 & 494 & 607 & 509 & 325 & 217 & 111 & 38 & 14 \\
\hline Pww & 2 & 42 & 152 & 301 & 460 & 463 & 421 & 316 & 219 & 171 \\
\hline \multicolumn{11}{|l|}{$\mathrm{SON}$} \\
\hline Pdw & 164 & 276 & 400 & 397 & 311 & 232 & 150 & 94 & 60 & 49 \\
\hline Pww & 87 & 190 & 312 & 344 & 411 & 389 & 353 & 270 & 200 & 316 \\
\hline
\end{tabular}


ated for the 4 seasons (DJF, MAM, JJA, SON) to take into account seasonal differences in the precipitation characteristics associated with any given magnitude of the air flow indices. These distributions are then resampled randomly to generate a new series of daily precipitation from the observed series of air flow indices.

Here, we use only vorticity to generate the distributions for 10 categories, ranging from less than -40 to over +40 units in steps of 10 . Although there is a certain degree of persistence in vorticity, in order to fully reproduce the persistence of wet and dry periods in the observed record, 2 additional rategories were defined: days were classified according to whether the previous day was wet or dry (see Fig. 10a, b). This leads to a total of 80 distributions.

Distribution sizes for Kempsford during the calibration period ranged from just 1 (for Durham, 2) event with vorticity less than -40 in JJA preceded by a wet day up to 665 (for Durham, 607) events with vorticity between -20 and -10 units in JJA following a dry day. The mean distribution sizes were 265 (Durham, 230) following dry days and 238 (Durham, 272) following wet days. Tables $2 \& 3$ list the distribution sizes for Kempsford and Durham respectively. The different size distributions (bins) reflect seasonal changes in the magnitude of vorticity (highest in DJF) and the increased likelihood of wet days following wet days at higher values of vorticity.

\subsection{Results}

Fig. 11a indicates that Model 1 faithfully reproduced the observed frequency distribution of wet day precipitation amounts at Durham during the 1936-1990 validation period. Even the frequency of the larger precipitation events $\left(>20 \mathrm{~mm} \mathrm{~d}^{-1}\right.$ ) was well represented (Fig. 11b). The model performed to a similar standard with the Kempsford data. Both models accurately reproduced the observed persistence of wet and dry day sequences at Durham and Kempsford. Fig. 12 shows mean annual frequency of wet and dry spell lengths, observed and simulated by Model 2 for both sites. The simulations slightly overestimate the number of short dry spells at the expense of longer dry spells at Kempsford and to a lesser extent Durham (where the number of long wet spells was also slightly underestimated). The daily data were aggregated into the annual mean and period mean statistics listed in Table 4.

In Model 1, the mean wet day amounts were underestimated by $5 \%$ at Durham and $11 \%$ at Kempsford. The number of wet days was overestimated by $1 \%$ at Durham and by $12 \%$ at Kempsford. These 2 errors combine to affect the mean annual total at Durham which was underestimated by Model 1. Model 2 produced 3 and $8 \%$ underestimates of wet day amounts at Durham and Kempsford, respectively. In nearly all cases, the models were found to underestimate the range and variance of annual precipitation totals, suggesting that the vorticity index alone is insufficient for capturing all of the observed variability in precipitation.

Both models capture a significant (to at least the $1 \%$ level) proportion of the interannual variability in annual precipitation (bottom row in Table 4). Improved 
representation of interannual variability may be achieved by using other variables, such as temperature. Part of this variability may result from processes acting on small scales, which cannot be accounted for by this method, and part of it may be the result of changes in the relationships between vorticity and precipitation over time.

Table 4 also lists the range of results obtained from 250 independent simulations of the 55 yr validation period using Model 2. These are shown as the maximum and minimum values recorded from the whole suite of simulations. The real world may be viewed as just 1 sample from an infinite population. The mean wet day amount and mean spell length are more sensitive to multiple simulations (ranging by roughly 10\%) than the wet day probability (roughly $4 \%$ ). In most cases, for the daily precipitation characteristics, the observed values still lie outside the simulated range. For the annual precipitation characteristics (means and ranges), however, the observed values generally lie within the simulated range. The widest variation occurs for the annual correlation between observed and simulated precipitation.

When the annual series of precipitation amounts and wet day frequencies were examined, Model 1 simulations were found to be weakly but significantly correlated (5\% level) with observed data. For example, Fig. 13 compares the observed and simulated $5 \mathrm{yr}$ running means of wet day frequencies at Kempsford, which were found to be correlated $(r=+0.64,0.1 \%$ level), yet with the observed values over-predicted by

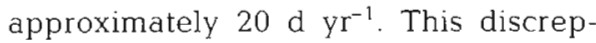
ancy was attributed to 2 possible sources of uncertainty: (1) the arbitrary definition of a wet day, which for modelling purposes was set at all non-zero rain days, or (2) a systematic change in the relationship between wet day probabilities and the prevailing vorticity. The residuals obtained from a regression analysis of the annual wet day frequency at Kempsford and the annual mean vorticity value display a marked change after 1945. It is unclear as to whether the trend in the residuals is due to changing site conditions (such as a change in the definition of wet days) or non-stationarity in precipitation-airflow relationships.
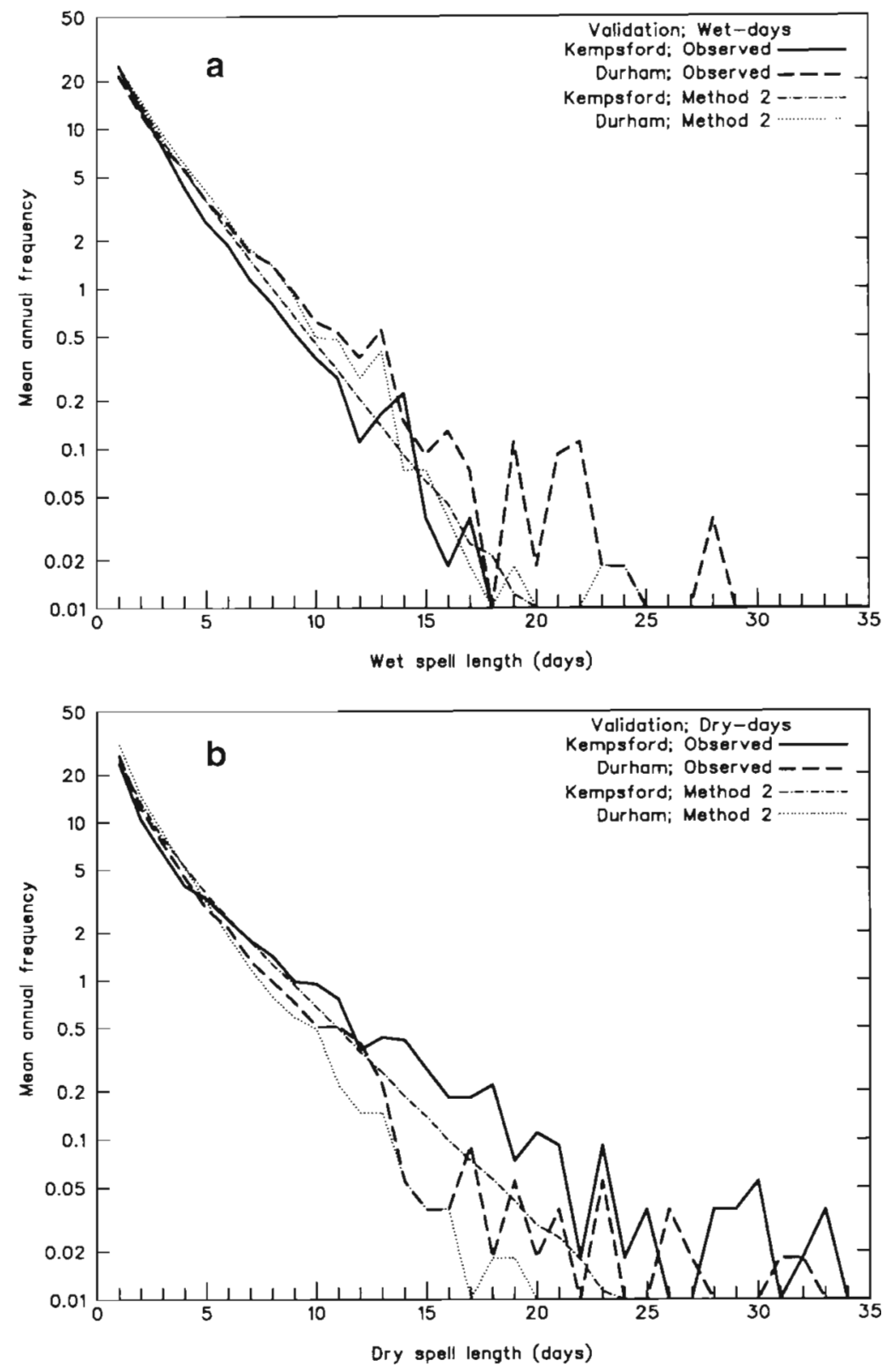

Fig. 12. Observed and simulated mean annual frequency of (a) wet and (b) dry spell lengths produced by Model 2 for Kempsford and Durham (validation period, 1936-1990)

\section{DISCUSSION AND CONCLUSIONS}

Our analysis of the relationships between 9 regional precipitation series in the British Isles and 3 air flow indices has highlighted significant regional differences. Vorticity exerts a strong influence on the probability of precipitation and the mean wet day amount in all 9 regions. Strength of flow and direction of flow exert a weaker influence that is more variable between regions. Regional differences in the precipitation char- 
Table 4. Observed and sımulated mean statistics for validation period. Example output from a single simulatıon of precipitation at Durham and Kempsford (1936-1990) by Model 1 and Model 2 (1 sim.). Maximum and minimum values for Model 2 represent the range of results obtained from 250 simulations of the validation period (where maximum and minimum statistics may come from different simulations)

\begin{tabular}{|c|c|c|c|c|c|c|c|c|c|c|}
\hline & \multicolumn{5}{|c|}{ Durham } & \multicolumn{5}{|c|}{ Kempsford } \\
\hline & \multirow{2}{*}{ Obs. } & \multirow{2}{*}{ Model 1} & \multicolumn{3}{|c|}{ Model 2} & \multirow{2}{*}{ Obs. } & \multirow{2}{*}{ Model 1} & \multicolumn{3}{|c|}{ Model 2} \\
\hline & & & Min. & $1 \mathrm{sim}$ & Max. & & & Min. & $1 \mathrm{sim}$ & Max. \\
\hline Mean wet day amount (mm) & 3.33 & 3.16 & 3.06 & 3.22 & 3.36 & 4.38 & 3.90 & 3.84 & 4.01 & 4.08 \\
\hline Wet day probability & 0.54 & 0.54 & 0.54 & 0.55 & 0.56 & 0.43 & 0.48 & 0.47 & 0.48 & 0.49 \\
\hline Mean dry spell (d) & 2.78 & 2.43 & 2.36 & 2.43 & 2.56 & 3.47 & 2.97 & 2.89 & 2.96 & 3.10 \\
\hline Mean wet spell (d) & 3.24 & 2.89 & 2.84 & 2.93 & 3.05 & 2.62 & 2.72 & 2.63 & 2.77 & 2.83 \\
\hline Mean annual total (mm) & 651 & 627 & 606 & 644 & 669 & 681 & 681 & 664 & 708 & 714 \\
\hline Max. annual total (mm) & 814 & 832 & 752 & 847 & 1092 & 994 & 884 & 818 & 986 & 1099 \\
\hline Min. annual total (mm) & 416 & 447 & 365 & 489 & 522 & 483 & 518 & 381 & 485 & 563 \\
\hline Range in annual totals (mm) & 399 & 385 & 284 & 339 & 630 & 511 & 366 & 301 & 482 & 628 \\
\hline Standard deviation (mm) & 104 & 89 & 68 & 76 & 118 & 106 & 99 & 77 & 101 & 123 \\
\hline Ann. corr with observed & - & 0.39 & 0.15 & 0.56 & 0.72 & - & 0.47 & 0.09 & 0.38 & 0.53 \\
\hline
\end{tabular}

acteristics associated with LWTs have been noted elsewhere, however, the use of air flow indices may provide greater insights into the physical causes of such variability. In some cases, smaller regional classifications may be used (e.g. Mayes 1991 for Scotland) or the objective scheme might be applied to a finer resolution pressure data-set.

Two methods of modelling daily precipitation using vorticity have been presented and compared. Both models produced reasonable simulations of the daily and annual characteristics of 2 single site series over an independent validation period. Model 1 is based on just 3 parameters (Pww, Pdw and R), whereas Model 2 is based on 10 categories of vorticity for each season and for whether the preceding day was wet or dry $(80$ distributions or bins). In spite of these differences in model structure, there are no outstanding differences in their ability to simulate the aspects of the time series analysed here.

\subsection{Application to other regions}

There is considerable potential to apply this technique to other regions because the 3 air flow indices possess a strong influence over the occurrence and magnitude of precipitation in many parts of the world. One useful quality of the method is its simplicity. This enables it to be easily adapted to take into account the different controls of precipitation in other regions. The analysis presented here of the regional precipita- tion series highlights the differences in their relationships with vorticity, flow strength and direction. As a more extreme example, we show in Fig. 14 the relationships between air flow indices and precipitation in western Switzerland (average of 4 sites: Berne, Fribourg, Neuchatel and Payerne, 1901-1990). Using the grid-point sea-level pressure data, air flow indices were calculated with the required set of 16 grid points centred over northern Italy and Switzerland $\left(10^{\circ} \mathrm{E}\right.$, $45^{\circ} \mathrm{N}$; see Jones et al. 1993 for details).

The frequency distributions of air flow indices over northern Italy and Switzerland are quite different to those over the British Isles (cf. Figs. $2 \& 14 \mathrm{a}, \mathrm{d}, \mathrm{g}$ ). Vorticity is much less pronounced at the extremes, with roughly $90 \%$ of values lying between -20 and +20 units. The strength of flow is also much weaker, with

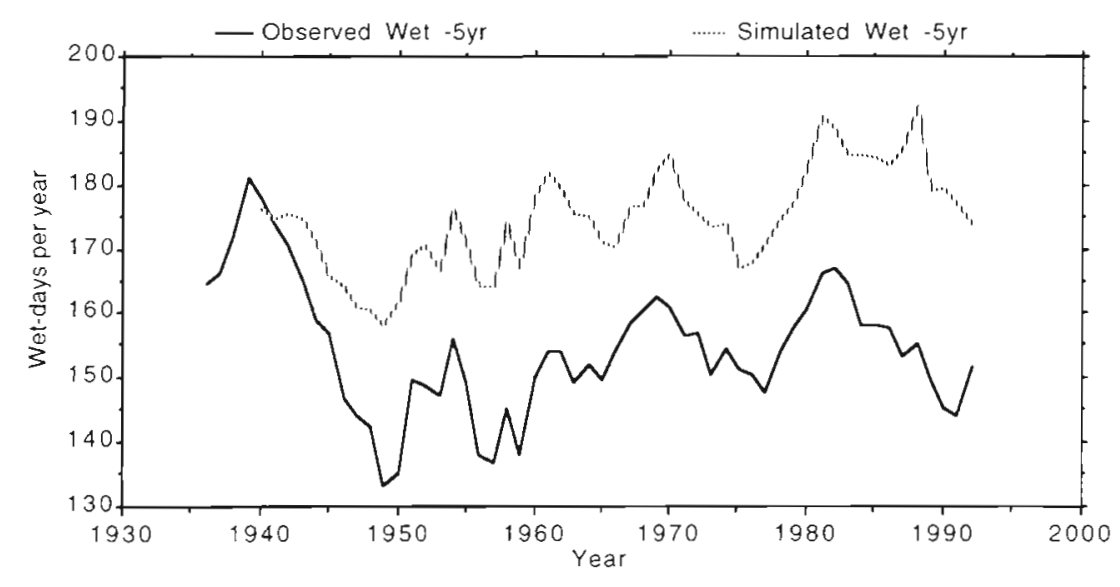

Fig. 13. Comparison of the observed and simulated 5 yr running mean of the annual wet day frequencies produced by Model 1 at Kempsford (validation period, 1936-1990) 
roughly $90 \%$ of values less than 16 units. Flow direction reflects the predominance of easterly and north-easterly winds in the region. The air flow indices clearly exert strong influences on the probability and magnitude of precipitation. There is an increase in the probability of precipitation with increasing vorticity but no change in the mean wet day amount. With strength of flow, however, there is little change in the probability of precipitation (except for an increase in events $>10 \mathrm{~mm}$ ) and a slight increase in the mean wet day amount. There are major differences in both the probability and magnitude of precipitation with flow direction. Easterlies bring less wet days and lower mean wet day amounts (at $80^{\circ}: 25 \%>0 \mathrm{~mm}$ and 3.5 to $4 \mathrm{~mm}$, respectively); westerlies bring more wet days and higher mean wet day amounts (at $270^{\circ}: 75 \%$ $>0$ and $7 \mathrm{~mm}$, respectively)

Application of either model to the Swiss example would require adapting it to best reflect these different relationships and possibly changes in temperature which also influence precipitation characteristics in the region (T. Brandsma \& T. A. Buishand unpubl.). It may also be possible to use atmospheric moisture if it proves to have a strong influence on $a b$ served precipitation characteristics, although long duration time series of this variable do not exist. In order to incorporate these additional factors and apply the method to other regions with different conditions, it may be necessary to apply more sophisticated techniques such as neural nets to define the relationships (Hewitson \& Crane 1996, this issue).
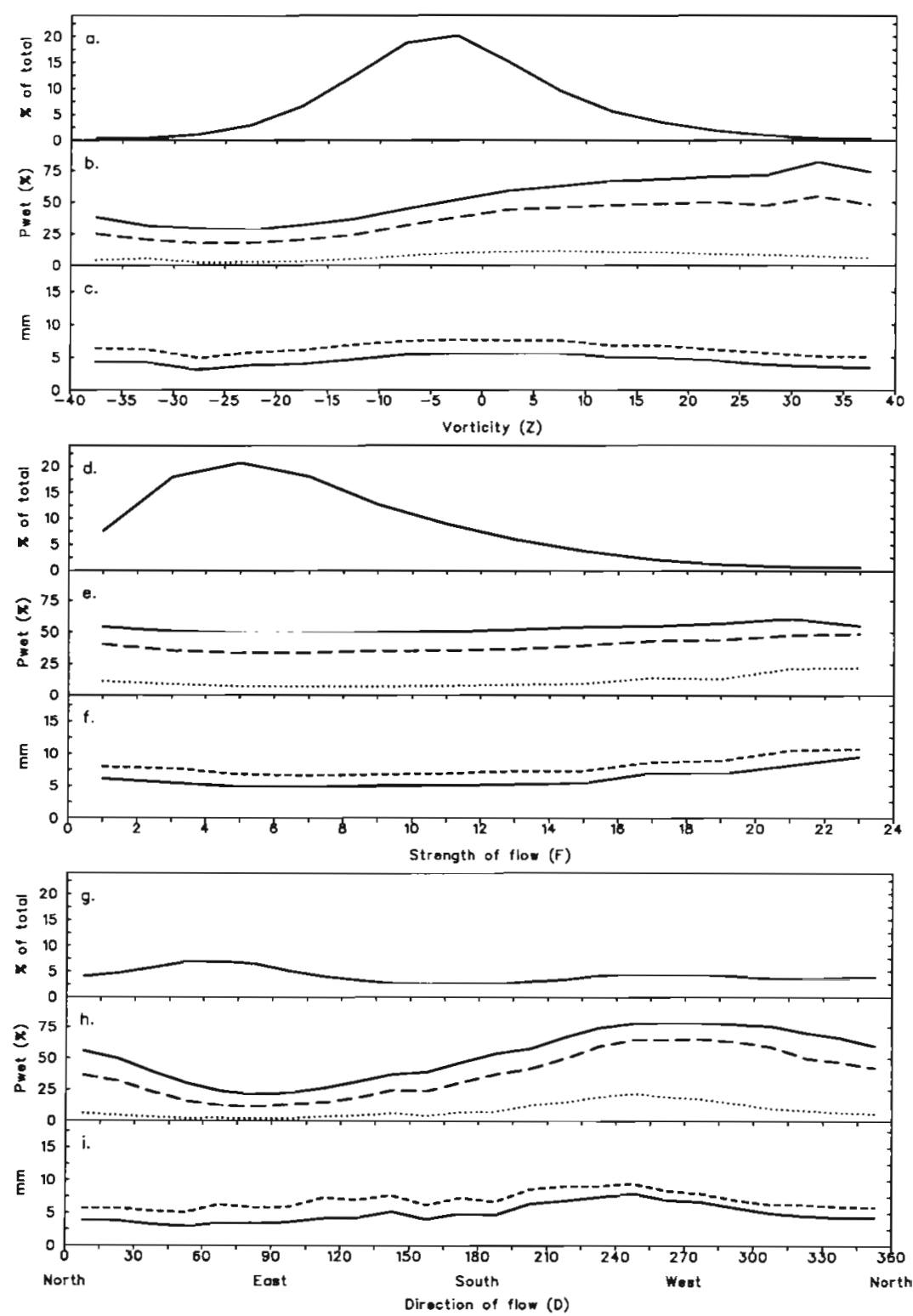

Fig. 14. Frequency distributions of air flow indices over Switzerland: (a) vorticity, (d) strength of flow, $(g)$ direction of flow. Relationships between air flow indices and daily precipitation (4-gauge average): percentage of days with precipitation $>0 \mathrm{~mm}(-),>1 \mathrm{~mm}(---)$ and $>10 \mathrm{~mm}(\cdots .$.$) for differing values$ of (b) vorticity, (e) strength of flow and (h) direction of flow. Mean precipitation amount for days $>0 \mathrm{~mm} \mathrm{(--)}$ and $>1 \mathrm{~mm}(----)$ for differing values of (c) vorticity, (f) strength of flow and (i) direction of flow. All values based on the period 1901-1990

\subsection{Application to GCM downscaling}

The results obtained from both models using only daily vorticity values are considered a valuable indicator of the potential for incorporating airflow indices in daily precipitation models with a view to GCM downscaling. Furthermore, the use of vorticity to model precipitation is physically meaningful and provides a datum against which more sophisticated approaches may subsequently be compared. For example, there is scope for the use of known regional and seasonal variations in the strength of flow to model regional and seasonal variations in precipitation, whilst the direction of flow could be used to simulate extreme precipitation events more realistically (Wilby in press).

Time series of the 3 air flow indices may be generated from GCM daily mean sea level pressure output. Comparison of control simulations with observations 
provides a useful means of validating GCM current climate simulations. Hulme et al. (1993), for instance, found that the temperature and precipitation characteristics associated with most of the 7 dominant LWTs (calculated from the air flow indices) occurring over the British Isles were reasonably well simulated on monthly time scales in 2 GCM control experiments. For many reasons the simulation of daily precipitation is more problematic, however, and it may be that the observed relationships between air flow indices and precipitation will not be preserved in the GCM simulation. Even validating these relationships is difficult because of scale problems between the GCM simulation of precipitation (averaged over a grid-box) and gauge measurements of point samples (Airey \& Hulme 1995). It may be necessary to derive regional relationships based on the mean values of a pre-determined number of gauges.

In order to generate daily precipitation scenarios, it is therefore necessary to utilise the GCM air flow indices (either directly or by calculating the control minus perturbed differences in values and variability) with the polynomial regression relationships in Model 1 or the event 'bins' in Model 2 derived from the observations. It should be possible to preserve spatial correlation in precipitation at a number of sites in a spatially coherent region of precipitation variation using Model 2. This may be achieved by binning the days at numerous sites based on the vorticity value and then sampling from precipitation events at a key site and using this day's precipitation at other sites within the same region (this may also be possible for nonprecipitation variables).

The assumption that the relationships between longterm precipitation statistics and the frequency of critical weather patterns or air flow types stay constant remains a major caveat of such downscaling approaches. The error in the number of modelled wet days at Kempsford suggests that this assumption is not always upheld. However, the exact source of this nonstationarity remains unclear, since long precipitation records for individual stations will probably contain subtle biases attributed to changing site conditions, instrumentation and/or observer bias with very low precipitation amounts. At the same time, the real possibitity of physical changes in the internal properties of air flow should not be overlooked. A detailed examination of the changing relationship between homogeneous regional precipitation series and dominant air flows would elucidate the significance of any non-stationarity and provide confidence intervals for future precipitation scenarios downscaled from GCM output. Future research in precipitation downscaling should also identify the key variables contributing to nonstationarity.
The generation of daily precipitation series remains a necessary precursor to a wide range of climate change impact analyses with a hydrological dimension (Wilby 1995b). However, Model 1 is presently limited by the absence of direct seasonal and inter-annual components. Clearly, the incorporation of these factors requires additional input data which could be provided by seasonal (Pww, Pdw and $R$ ) relationships, the flow strength and direction indices or by weather front data (Wilby et al. 1995). Use of weather front data for scenario construction will be constrained by how well they are simulated in GCMs - which at their current level of resolution is very limited. Model 2 may work with fewer vorticity categories. Other potential improvements might include the use of temperature, atmospheric moisture content, flow strength or direction and information about the previous day's vorticity to represent the development of the circulation system. Application of either model to other rogions may rcquire use of more sophisticated techniques such as neural nets to define the relationships between precipitation and air flow indices. In conclusion, the use of air flow indices clearly represents a significant opportunity for developing a downscaling method that is neither subjective nor regionally specific. The comparison of 2 models presented here highlights the potential for developing a hybrid model based on the successful attributes of each one.

Acknowledgements. This research was supported by the European Community Environment Research Programme (contract: EV5V-CT-94-0510, Climatology and Natural Hazards). The data of Gregory et al. (1991) were made available by agreement of Tom Wigley and Phil Jones of the Climatic Research Unit of the University of East Anglia and John Cole of the Water Research Centre. Daily precipitation data for Switzerland were made available by the Swiss Meteorological Institute, Zurich. The comments of 3 anonymous referees and Hans von Storch have improved the content of this paper.

\section{LITERATURE CITED}

Airey M, Hulme MH (1995) Evaluating climate model simulations of precipitation: methods, problems and performance. Prog Phys Geog 19:427-448

Bardossy A, Plate EJ (1991) Space-time model for daily rainfall using atmospheric circulation patterns. Water Resour Res 28:1247-1259

Conway D, Jones PD (in press) The use of weather types and air flow indices for GCM downscaling. J Hydrol

Davies TD, Kelly PM, Brimblecombe P. Farmer G, Barthelmie RJ (1986) Acidity of Scottish ranfall influenced by climatic change. Nature 232:359-361

Gregory JM, Jones PD, Wigley TML (1991) Precipitation in Britain: an analysis of area-average data updated to 1989 Int $J$ Clim 11:331-345

Hay LE, McCabe GJ, Wolock DM, Ayers MA (1991) Use of weather types to disaggregate general circulation model predictions. J Geophys Res 97:2781-2790 
Hewitson BC, Crane RG (1996) Climate downscaling: techniques and application. Clim Res 7:85-95

Hulme M, Briffa KR, Jones PD, Senior CA (1993) Validation of GCM control simulations using indices of daily airflow types over the British Isles. Clim Dyn 9:95-105

Hulme M, Wigley TML, Jones PD (1990) Limitations of regional climate scenarios for impact analysıs. In: Boer MM, De Groot RS (eds) Landscape-Ecological Impact of Climate Change. IOP Press, Amsterdam, p 111-129

Jones PD. Hulme M, Briffa KR (1993) A comparison of Lamb circulation types with an objective classification scheme. Int J Clim 13:655-663

Lamb HH (1972) British Isles weather types and a register of the daily sequence of circulation patterns 1861-1971 Meteorol Office Geophys Mem 116. HMSO, London

Mayes JC (1991) Regional airflow patterns in the British Isles. Int J Clim 11:473-491

O'Hare GP, Wilby R (1995) A review of ozone pollution in the United Kingdom and Ireland with an analysis using Lamb Weather Types. Geogr J 161:1-20

Sweeney JC, O'Hare GP (1992) Geographical variations in precipitation yields and circulation types in Britain and Ireland. Trans Inst Br Geogr 17:448-463

von Storch H, Zorita E, Cubasch U (1993) Downscaling of global climate change estimates to regional scales:

Editor: H. von Storch, Geesthacht, Germany an application to lberian rainfall in wintertime. J Clim 6 : $1161-1171$

Wigley TMl., Jones PD (1987) England and Wales precipitation: a discussion of recent changes in varability and an update to 1985 . J Climatol 7:231-246

Wigley TML, Lough JM, Jones PD (1984) Spatıal patterns of precipitation in England and Wales and a revised, homogeneous England and Wales precipitation series. J Climatol 1:283-294

Wilby RL (1994) Stochastic weather type simulation for regional climate change impact assessment. Water Resour Res 30:3395-3453

Wilby RL (1995a) Simulation of precipitation by weather pattern and frontal analysis. J Hydrol 173:91-109

Wilby RL (1995b) Greenhouse hydrology. Prog Phys Geogr 19:351-369

Wilby RL (in press) Modelling low frequency rainfall events using air flow indices, weather patterns and frontal frequencies. J Hydrol

Wilby RL, Barnsley N, O'Hare G (1995) Rainfall variability associated with Lamb Weather Types: the case for incorporating weather fronts. Int J Clim 15:1241-1252

Wilby RL, Greenfield B, Glenny C (1994) A coupled synoptichydrological model for climate change impact assessment. J Hydrol 153:265-290

Manuscript first received: December 24, 1995

Revised version accepted: July 9, 1996 